\title{
Ayer y hoy: la apuesta universitaria y juvenil por la revolución "say no more"
}

\section{Resumen}

Un fantasma recorre el mundo: el fantasma del ¡Say No More! Decir “no más” es una cuestión de rebeldía y voluntad. Así define Camus (1982) las cualidades que hacen posible la liberación del hombre y su espíritu. Ahora bien, la rebeldía y la voluntad modulan hace exactamente cincuenta años los hechos y las pretensiones para una nueva forma de ver el porvenir. Los exponentes de este cambio son los jóvenes de todo el mundo. El descontento va de la mano con un mundo de posibilidades, experiencias e ilusiones. Este artículo sintetiza y presenta al estudiantado como un actor en la búsqueda de resolver su devenir. Para ello, presenta a la universidad como un territorio donde se agrupan y desenvuelven históricamente generaciones estudiantiles movidas por la revolución y el deseo de cambio a partir del año de 1968. La movilización expresa cambios y puede, a su vez, mostrar una trazabilidad de aspiraciones y conceptos que emplean los jóvenes con un elemento en común: la necesidad de decir "no más".

Palabras Clave: juventud, movimiento estudiantil, revolución, universidad

\section{Abstract}

A ghost travels the world: the ghost of Say no more! Saying "no more" is a matter of rebellion and will. Camus (1982) defines the qualities that make possible the liberation of man and his spirit. However, the rebellion and the will modulated exactly fifty years ago the facts and the pretensions for a new way of seeing the future. The exponents of this change are young people from all over the world. Discontent goes hand in hand with a world of possibilities, experiences and illusions. This article synthesizes and presents the student body as an actor in the search to solve his becoming. It presents the university as a territory where student generations moved by the revolution and the desire for change from the year 1968 that historically the universities were grouped and were developed. The mobilization expresses changes and show a traceability of aspirations and concepts that young people use with one element in common: the need to say "no more".

Keywords: youth, student movement, revolution, university

POR ÁlVARo aCEVEdo tarazona/AndRÉS CORREA-LUGOS. Doctor en Historia. Profesor Titular Universidad Industrial de Santander. Director del Grupo de Investigación Políticas, Sociabilidades y Representaciones Histórico-Educativas (Psorhe). tarazona20@gmail.com; acetara@uis.edu.co. / Historiador y Archivista de la Universidad Industrial de Santander. Estudiante de maestría en Historia de la Universidad Industrial de Santander. Miembro del Grupo de Investigación Políticas, Sociabilidades y Representaciones Histórico-Educativas. andrescorrealugos@outlook.com. 


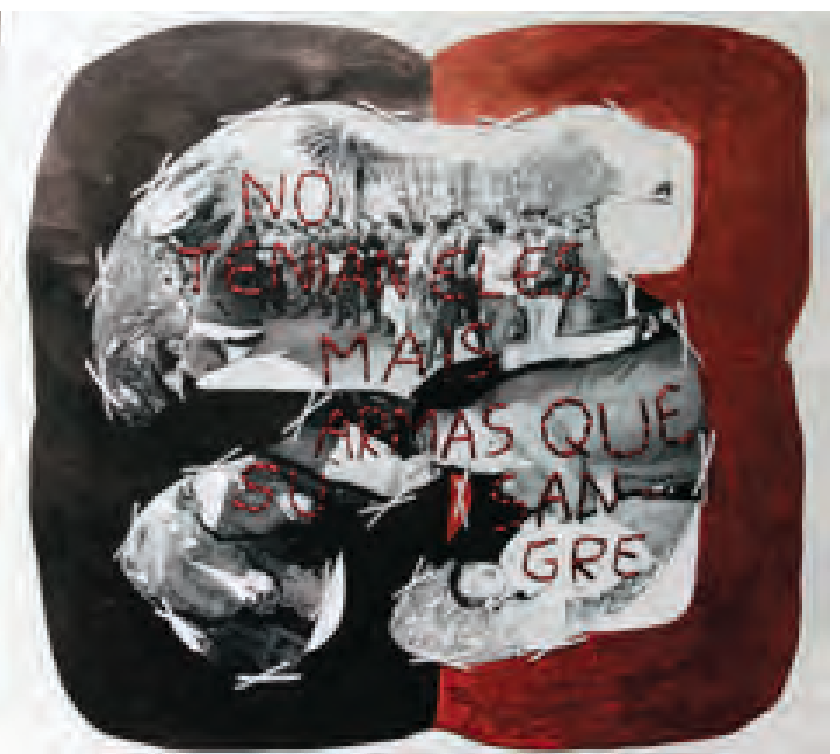

Gabriel Fogliarini (Brasil), Sin título, fotografía intervenida técnica mixta, 2018 / Archivo Histórico de la UNAM / IISUE-AHUNAM

\section{Resumo}

Um fantasma percorre o mundo: o fantasma do Say no more! Dizer "não mais" é uma questão de rebeldia e vontade. Assim Camus (1982) define as qualidades que fazem possível a libertação do homem e do seu espirito. Agora bem, faz exatamente cinquenta anos que a rebeldia e a vontade modularam os fatos e as pretensões para uma nova forma de assistir o futuro. Os exponentes desta mudança são os jovens do mundo tudo. O descontento vai da mão com um mundo de possibilidades, experiências e ilusões. Este artigo resume e apresenta aos estudantes como um ator na procura de resolver seu acontecer. Para isso, apresenta-se à universidade como um território onde agrupam-se e desenvolvem-se historicamente gerações estudantis movimentadas pela revolução e o desejo de uma mudança a partir do ano de 1968. A mobilização expressa mudanças e pode, ao mesmo tempo, mostrar os traços das asipiracões e conceitos que são utilizados pelos jovens com um elemento em comum: a necessidades de dizer "não mais".

Palabras Clave: juventude, movimento estudantil, revolução, universidade

\section{Exordio a la revolución eterna}

La juventud es una fuerza que no se conforma. La realización de los cambios en manos de personas que consideran que aún todo es posible o que todo está por mejorar es la base de la innovación, los sueños y las utopías. A partir de esta fuerza inconforme es que el siglo XX logra ser lo que es: un corto pero nutrido siglo de coyunturas (algunas nos llenan de orgullo y otras no tanto). En retrospectiva, son experiencias que animan a la comprensión y el recuerdo de que estamos vivos en este preciso instante, gracias al acumulado de luchas y reivindicaciones sociales y, ante todo, de personas que creyeron en una revolución que cambiase el estado de cosas existentes, así la llegada de la misma continúe posponiéndose hasta parecer eterna.

Retomando lo planteado por Nietzsche (2006, 63): "yo amo a quienes no saben vivir de otro modo que hundiéndose en su ocaso, pues ellos son los que pasan al otro lado", esta disertación es un reconocimiento a aquellos hombres y mujeres que no buscaron protagonismo en el momento que anhelaron el cambio; por el contrario, quisieron el anonimato y hoy recuerdan lo vivido mientras ríen de aquellos sabios o expertos que consideran la revolución como un ocaso. Actualmente desde la sabiduría y calma que brinda el tiempo transcurrido, casi medio siglo, les ha hecho entender que el abrazo de la historia está lleno de contrariedad, pulsión y desazón. Aun así, las experiencias se convierten en un memento vivere que retoma la postrimería revolucionaria y resalta la vida y obra de quienes creyeron en él y donaron sus juventudes a una causa de cambio. Los movimientos sociales y los intentos de revolución son coyunturas que evocan a la historia para la vida, pues se abren paso a través de la existencia del absurdo y ven en su momento histórico una posibilidad única para revertir la angustia de la existencia y resignificar el porvenir.

Este artículo se interroga por la revolución cultural del año 1968, como acontecimiento planetario y con impacto inmediato en la década de los años setenta del siglo XX en Colombia con la propuesta de cogobierno universitario, la renovación de la izquierda en Colombia e interesantes propuestas políticas y culturales que abren un país hermético, sumido en una especie de Tíbet suramericano. 
El 68 representa una inflexión en el acontecer de la apuesta juvenil colombiana, pero no debe ser visto desde una lógica de los resultados; su acontecer es expresión de un acumulado de fuerzas y tensiones sociales. No es importante si se consigue o no una revolución, lo importante es el proceso que conduce a su enunciación y materialización (Deleuze, Diálogos 2013, 6). Ahora bien, al considerar este acontecimiento en su devenir, la importancia no radica en su facticidad misma, sino en los efectos que este tiene en la geografía vital, en nuestro espacio más inmediato. Su devenir tiende a transformar la territorialidad de la universidad, la cual deja de ser la connotación de un territorio estructurado propio de una institución de educación para el desarrollo del saber y la apuesta por la movilidad social hasta convertirse en un territorio donde convergen las ideas, la crítica social, el arte, la ciencia y, en especial, la rebeldía.

\section{La juventud es una fuerza que}

no se conforma. La realización

de los cambios en manos de personas

que consideran que aún todo es posible

o que todo está por mejorar es la base de la innovación, los sueños y las utopías. A partir de esta fuerza inconforme es que el siglo XX logra ser lo que es: un corto pero nutrido siglo de coyunturas (algunas nos llenan de orgullo y otras no tanto).

\section{El año que la rebeldía se tomó el mundo}

Corría el año de 1968, el clima de la posguerra se podría considerar como insoportable. Los gobiernos norteamericanos se mueven a diestra y siniestra por un mundo que creen suyo y los gobiernos soviéticos mandan detrás de una cortina de hierro. Mientras las potencias se aferran a la conquista del espacio, aquí los simples mortales se aferran con vehemencia a un mundo del cual solo son pasajeros en trance. El hecho de pensar un mundo dividido en dos regímenes con la capacidad de destruirse a su antojo, con el simple hecho de presionar un botón, es un hervidero de cons- piraciones. Es imposible que una generación nacida en medio de este panorama no intente rebelarse. En medio de este malestar se produce un acontecimiento que desnuda al planeta entero: hay una Guerra Fría y dos regímenes políticos basados en el miedo y la latencia. Y así es como una revolución de hábitos, consumos e ideas toman las universidades, avenidas y plazas. Los movimientos sociales son los barómetros que indican la presión de tales acontecimientos y aportan el material humano, la carne y las ilusiones para llenar calles mientras gritan al unísono: ¡No más!

Lo que pasó en el año de 1968 es único; no se ha repetido en el siglo XX una alucinación juvenil de las mismas proporciones. La rebeldía y los vientos de revolución desde China y Francia inspiraron juventudes enteras, de la misma manera que lo acontecido poco antes en los Estados Unidos en las marchas y demandas por los derechos civiles. Lo que pasó para el mundo desde aquel mes de mayo fue un síntoma generacional, ¿pero un síntoma de qué? Bien, estos jóvenes son la primera generación alejada del recuerdo de la Segunda Guerra Mundial; además es la primera generación hija de la latencia, viven con la certeza de una presencia que no ven, de un polizón que quieren echar del barco, pero no lo encuentran. Huyen del pasado, pero ignoran que este define su futuro (Gumbrecht, 2015). Un futuro que se ha congelado en un ancho presente. De manera que su lucha es por el futuro, por un nuevo futuro. En otras palabras, su lucha es contra el tiempo. La apuesta es el futuro en un pasado que se difumina y rechaza, sobre todo la tradición.

Los jóvenes del 68 anhelan cambiar ya el futuro, no tienen nada por recordar ni desean hacerlo; la historia es un referente más y consideran que cualquier acontecimiento que marque el mundo debe marcar su propio rumbo. Ellos están latentes, suspendidos a la espera de un cambio ya, entre la rebeldía, la lógica absurda, el sincretismo del consumo material y de ideologías y un tiempo acelerado que se ensancha y ensancha en un eterno presente. Un pliegue en la flecha del tiempo, sin pasado ni futuro, sin transiciones. ¿Son conscientes de ello? No. Muy pocos, casi nadie es consciente de ello. El pintor Pollock lo avizora en su cuadro No. 28 al igual que el poeta Pilinszky, y en 1974, a sus 85 años, solo, muy solo y desgarrado, apesadumbrado, despidiéndose del mundo, Heidegger: 


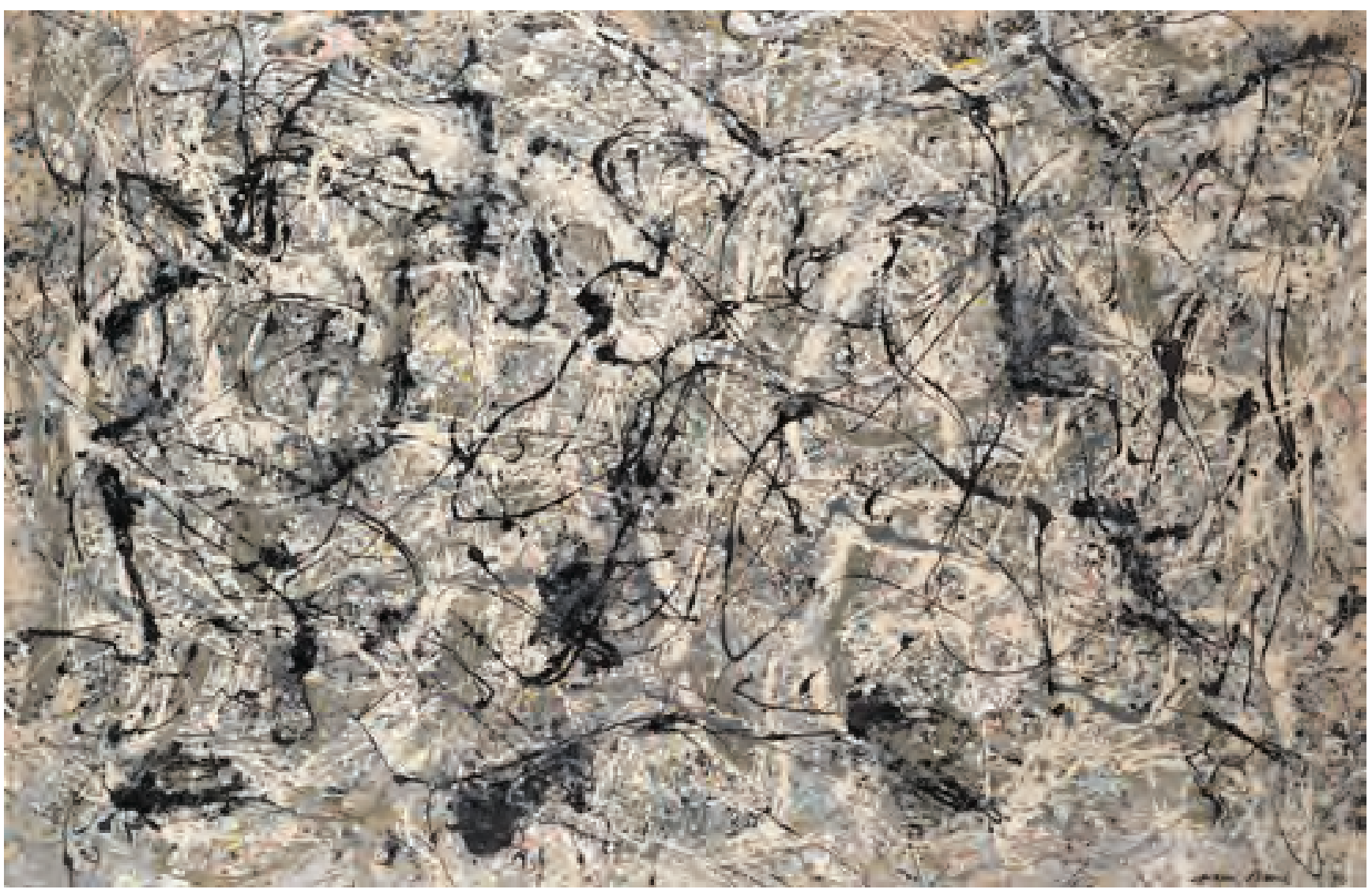

Jackson Pollock. \#28. New York. 1950.

Más elemental que la poesía, más fundacional que el pensar debe permanecer la gratitud. Volverás a traer a aquello que vienen al pensar la presencia de lo inaccesible hacia lo que nosotros -mortales sin excepciónsomos dados desde el origen $(2015,74)$.

Un dolor y entrega que ya constataba Pilinszky (Apócrifos, 1950-1955):

El silencio de los cielos se dejará a un lado y para siempre a un lado.

Los campos rotos del mundo acabado y a un lado el silencio de las perreras. En el aire una bandada voladora de pájaros y veremos el Sol naciente mudo como la pupila demencial de un ojo y calmo como una bestia mirando $(2015,197)$.
La aceleración del tiempo los lleva a no tolerar la represión y el descarrilamiento hacia los valores neo-conservaduristas. La implementación de un panóptico que controle las incursiones nocturnas de los jóvenes a las habitaciones de las señoritas es un detonante, y muy serio, de una represión que pretende migrar de los estrados políticos a los cuerpos y el deseo: ¡No más! De pronto el polvorín recorre las universidades, los cafetines y en especial las paredes parisinas. Las universidades se transforman en sitios de camaradería, el tráfico de ideas consideradas contrarias al establishment se reproduce exponencialmente; el virus de la revolución se ha tomado el cuerpo sin órganos que es la sociedad y los jóvenes están en un estado febril.

La primera revolución a pequeña escala se da dentro de las universidades; las paredes gritan, la fugacidad de la rebeldía transforma el territorio dentro de los campus. El mundo entero asiste el baile de la revolución: los policías, los padres, la iglesia y todo aquello que tenga alguna traza de autoridad es combatido. Cada 
rasgo del 68 en cada país es distinto, pero se pueden sacar síntesis continentales.

Igualmente, Guy Debord bautiza a los jóvenes del 68 como los escenógrafos de mayo. La nostalgia que producen los rostros amotinados y las paredes coloridas permite crear una atmósfera en la cual en ese instante, hay una auténtica interrupción de la historia. Lo que pasó en Francia de la mano de los estudiantes de artes de las universidades, los trabajadores de la Renault y los sindicatos es la apertura de los sectores populares al mercado del ocio y la abundancia. Esta revolución cultural promovió millones de dólares mientras que por el primer mundo se pone en boga el "American Way of Life" (La sociedad del espectáculo 2010, 9): el turismo de experiencias y la indignación no por convicción, sino por moda. Ser revolucionario es ser profano, y lo profano es vanguardista, contracultural.

A la par que los estudiantes marchaban en Francia, el cineasta Jean Luc Godard filma Simpathy for the Devil, un documental que explora las profundas tensiones de la Guerra de Vietnam, las panteras negras y el aborto, en sincronía con la canción de los Rolling Stones que lleva el mismo nombre. Godard, un profeso maoísta, dice que la generación del 68 es testigo de los errores y los horrores del siglo entero; ellos conocían lo que había pasado, pero no lo querían tener presente, se habían convertido en demonios insensibles, pero con estilo frente a un devenir de destrucción:

Estaba cerca San Petersburgo cuando vi que había llegado el cambio.

Maté al zar y a sus ministros

Anastasia gritó en vano.

Conduje un tanque, tenía el rango de general cuando estalló la guerra relámpago

y los cuerpos hedían.

Grité: ¿quién mató a los Kennedy? cuando después de todo fuimos tú y yo. Tendí trampas a los trovadores que murieron antes de llegar a Bombay.

Al igual que cada policía es un criminal todos los pecadores santos y cara o cruz es lo mismo llámame simplemente Lucifer (Jagger 1968).
Lo que fue el año de 1968 apenas comienza a dilucidarse. En medio del fogueo y la intensidad pulsional que representa ser parte de un sentimiento a escala planetaria, había voces críticas que desnudan lo que pasó en aquellos meses en el mundo entero. Amado por unos y abucheado por otros, Paolo Pasolini fue una de las mentes más mordaces, críticas y ácidas de Europa, ante la escalada de estudiantes en las protestas de la capital italiana, el artista respondió por medio de un poema:

Es triste.

La polémica contra el PCI ya se dio en la primera mitad de la pasada década.

Vais con retraso, hijitos.

Y carece de toda importancia que aún no hubierais nacido...

Además, los periodistas de todo el mundo (incluidos los de las televisiones)

os lamen -todavía, creo, se dice así en la jerga universitaria- el culo. Yo no, amiguitos.

Tenéis cara de hijos de papá.

Que la buena casta no engaña.

La misma mirada maligna.

Sois miedosos e irresolutos y estáis desesperados

(¡magnífico!), pero también sabéis cómo ser

prepotentes, desafiantes y seguros:

prerrogativas pequeño-burguesas, amiguitos.

Cuando ayer en Valle Giulia os liasteis a mamporros con los polizontes,

¡yo simpatizaba con los polizontes!

Porque los polizontes son hijos de pobres.

Vienen de las periferias: campesinas o urbanas, no importa.

En lo que a mí hace, conozco muy bien su modo de haber sido chiquillos y muchachos, las preciosas mil liras, el padre que tampoco dejó de ser un muchacho

por causa de esa miseria que no confiere autoridad. La madre, encallecida como un portero, o tierna, por alguna enfermedad, como un pajarito;

los muchos hermanos, la choza

tras los huertos con la salvia roja (en terrenos ajenos, parcelados);

los bajos sobre las cloacas; o los apartamentos en los grandes complejos de vivienda popular, etc. etc. 
Y bien, mirad cómo visten: como payasos, con aquel paño áspero que huele a rancho furrielero y a pueblo. Lo peor de todo, naturalmente, es el estado psicológico al que se ven reducidos (por cuarenta mil liras mensuales): horros de sonrisas,

horros de amistades con el mundo, separados, excluidos (con una exclusión sin par); humillados por la pérdida de la calidad de hombres a trueque de la de polizontes (ser odiado hace odiar).

Tienen veinte años, vuestra edad, queridos y queridas.

Estamos todos, ni qué decir tiene, contra la institución de la policía.

¡Pero tomadla con el sistema judicial, que ya veréis! Los muchachos polizontes

A los que, con sacro gamberrismo (de premeditada tradición resurgimentista)

de hijos de papá, habéis apaleado,

pertenecen a la otra clase social.

En Valle Giulia, ayer,

se desarrolló, pues, un episodio

de lucha de clases: y vosotros, amiguitos (bien que en el bando de la razón) erais los ricos,

mientras que los polizontes (que estaban en el bando equivocado) eran los pobres.

¡Bonita victoria, pues, la vuestra! Y en esos casos, amiguitos, las flores se dan a los polizontes (Pasolini 1968).

La visión apasionada del mayo del 68 en todo el mundo está impulsada por aquellos que en su momento fueron estudiantes y posteriormente escriben una justificación de sus actos. Sin embargo, en Latinoamérica la rebeldía y pretensión revolucionaria es distinta. No existió un efecto mediático que posicionara una perfomance de la revolución y el progresismo; por el contrario, la rebeldía que mueve a los estudiantes desde 1968 está basada en un espíritu de resistencia y lucha contra un sistema violento y represivo que adopta medidas de seguridad nacional desde la lógica geopolítica de los Estados Unidos. Si bien desde el año de 1918 en Córdoba, Argentina, los estudiantes rechazan los alcances imperialistas del "vecino del norte", como llaman a los Estados Unidos (Tünnermann 2008), las dos guerras mundiales y la consolidación de una perspectiva norteamericana del capitalismo conduce a una fuerte influencia en la política, la economía y la cultura.

Una de las características que distancia el 68 en Latinoamérica y Europa es la consolidación de la clase media: es cierto que en nuestro continente también va en un crecimiento paulatino, pero los estudiantes y los jóvenes se quejan del aumento de la brecha de desigualdad social, un fenómeno que multiplica la violencia, la criminalidad y las malas prácticas gubernamentales. En síntesis, lo que pasa a partir de 1968 en Latinoamérica es la consolidación de una conciencia política que ve en las formas de lucha una alternativa viable para ubicar en el radar del mundo una forma de pensar que está en desacuerdo con los planes de una minoría que controla el porvenir de los más jóvenes.

\section{El 68 en Colombia}

Para el caso colombiano, los edificios y las plazoletas son rebautizados con héroes de revolución como el Che Guevara o Camilo Torres (Acevedo, Memorias de una época 2016, 55). Desde Bucaramanga hasta Pekín, las paredes de las universidades se llenan paulatinamente de dazibaos; lo que la urbanidad y buenas costumbres han transmitido por décadas bajo el lema "la pared y la muralla son el papel del canalla" es transgredido en cuestión de meses con el ideal de la revolución por esta nueva generación. Los jóvenes querían escribir para todos, sin miedo a transmitir las ideas que albergaban y que anteriormente solo compartían con sus más cercanos amigos. Las pintas en la pared son un libro abierto. El 68 fue un grito colectivo que exigía el cambio y criticaba la forma como se había administrado la política, la economía y la sociedad en general.

Distintos a los jóvenes nadaístas que los antecedieron con aquella emblemática expresión "¿tienen derecho, un puñado de flores, a proclamarse reformadoras del jardín tan sólo por la gracia de florecer?" (E. Escobar 2005), la generación del 68 tiene una clara conciencia política y reconoce el papel activo de la universidad que consiste, precisamente, en cambiar la sociedad. Los vientos de transformación recorren todo el continente y en ellos se escucha la consigna de "Prohibido prohibir". Ahora bien, si en Norteamérica y 
Europa el consumo y las libertades son transversales a la revolución, en Colombia el proceso es algo distinto. El 68 alimenta el discurso de las luchas guerrilleras, la vía armada para la liberación de los pueblos del yugo opresor, y de alguna manera logra capturar en ciertas tendencias de la nueva izquierda la aversión contra el oficialismo y antepone la lucha armada como sumatoria de todos los medios de lucha para alcanzar la revolución. La izquierda revolucionaria es la única opción y no hay ni siquiera posibilidad de acuerdo con los militantes del PCC y los "niños bien" de la Juventud Patriótica del Moir. Estos últimos quieren la revolución después de las condiciones materiales y políticas que permitan hacer posible la revolución. No hay tiempo, argumenta la izquierda revolucionaria, cualquier transacción con el capitalismo es un devaneo pequeño burgués y una traición a la revolución (Acevedo, 1968: Historia de un acontecimiento 2017, 291).

\section{Una de las características que distancia el 68 en Latinoamérica y Europa es la consolidación de la clase media: es cierto que en nuestro continente también va en un crecimiento paulatino, pero los estudiantes y los jóvenes se quejan del aumento de la brecha de desigualdad social, un fenómeno que multiplica la violencia, la criminalidad y las malas prácticas gubernamentales.}

De la mano de las lógicas comunistas y anarquistas, los acontecimientos pos-68 en Colombia reemplazan en ciertos jóvenes universitarios el yugo judeocristiano por el yugo marxista-leninista. Ser revolucionario no era sinónimo de libertades, experiencias o viajes psicodélicos. De hecho, los sectores estudiantiles más ortodoxos rechazan cualquier tipo de libertad al considerarla como placeres pequeño-burgueses. En vista de ello, para tratar de compensar las prohibiciones, se crean nuevas líneas de fuga para alcanzar sensaciones o satisfacciones en el libre mercado y el consumo. Por ejemplo, el cine era considerado como una manipulación por parte del capitalismo y la oligarquía; por esta razón se fortalece el teatro, siempre y cuando tenga fines revolucionarios que ilustren y conlleven a la "conciencia de clase". Las adaptaciones de Jairo Aníbal Niño en los teatros universitarios e incluso obras específicas como La madre de Gorky son verdaderas puestas en escena que causan furor en las universidades públicas colombianas y alientan la rebeldía (Mejía 2016).

La prohibición iba más allá del cine y migraba a otras formas de entretenimiento. La década de los sesenta y setenta es famosa por la libertad sexual. De hecho, Philip Roth aduce que ha sido la única revolución que ha triunfado; fenómenos como la minifalda en la experiencia estética del cuerpo o la masificación de los anticonceptivos en el plano científico y social son síntomas de un cambio en la concepción del cuerpo y la relación con el otro; sin embargo, desinhibiciones y descubrimientos en el cuerpo no son tanto en nuestro acontecer colombiano. Casi como parte de un catecismo, revistas del Partido Comunista como Juventud prohibían cualquier alusión a la pornografía al considerarla como un vicio burgués que promovía la individualización y ocupaba tiempo valioso que podría servir para pensar la revolución (Voz proletaria 1976). La psicodelia de las drogas también llegó a medias a nuestro acontecer. Si bien hay festivales de música y jipismo como el de Ancón, en Medellín, donde cuentan que era tal el desenfreno que el párroco tuvo que sacar a los jóvenes a fuetazos, dentro del rigor comunista y de izquierda la droga era vista como el artilugio del imperialismo para justificar los neocolonialismos y la intervención norteamericana en el continente. El placer estaba vetado, el deseo solo podía ser por la revolución y la satisfacción no estaba concebida más allá del heroísmo y sacrificio guerrillero (Sancho 2008).

El carácter restrictivo en ciertas tendencias de la izquierda da pie a unas nuevas que no rompieron con la verticalidad de pensamiento y acción; en ciertos casos, se cubrieron con una nueva retórica y una nueva imitación: la Revolución Pro-China. Muy distinto a lo que pasaba en Francia: el bestseller del 68 es Diferencia y repetición de Gilles Deleuze (1968), un libro que explora el contenido de la libertad a partir del deseo de desear. La revolución cultural en Colombia no promueve la libertad en sí misma, ni siquiera al considerarnos máquinas deseantes; seguimos emulando el ideal misionero, 


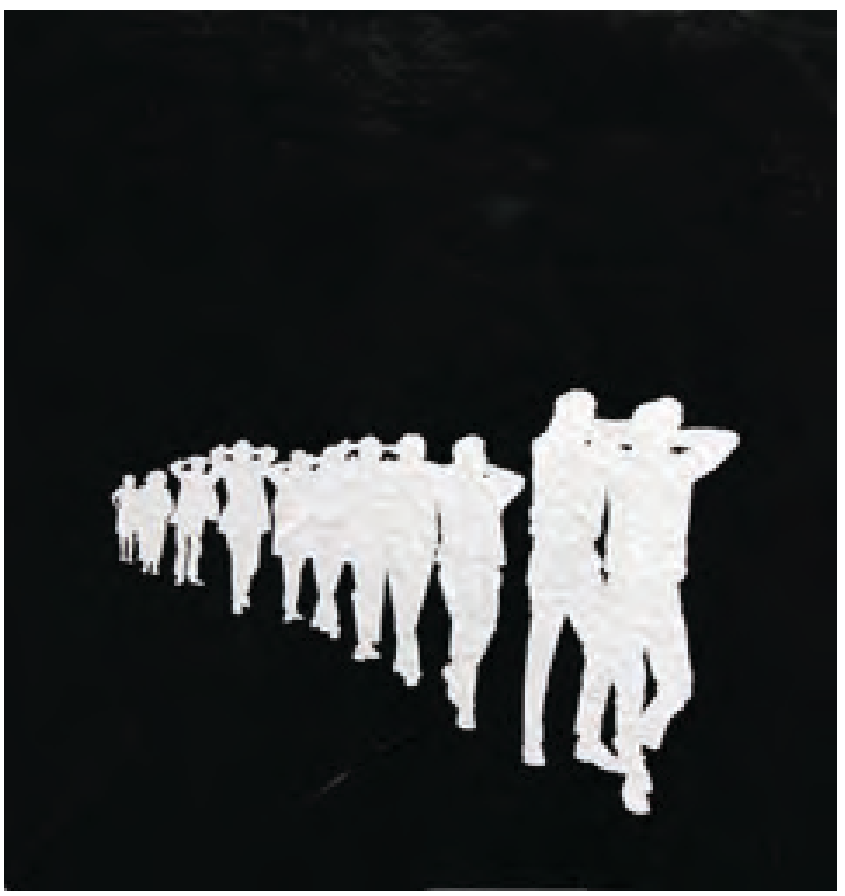

Yohnattan Mignot (Uruguay), Sin título, fotografía intervenida, 2018 / Archivo Histórico de la UNAM / IISUE-AHUNAM seguimos pensando que somos los hijos predilectos de un Dios que puede juzgar, y solo vemos el mundo como un todo monocromático en el que la lucha se da en términos de lo que es distinto a mí es mi enemigo. Este ideal desdibuja al otro y puede llegar a convertirse en una sola elección: enfrentarse al otro con violencia. De nuevo vale la pena traer a William Blake, quien para 1790 escribió en Las bodas del cielo y el infierno:

Aquellos que restringen el deseo lo hacen porque el suyo es lo suficientemente débil como para ser restringido; y entonces aquel que restringe la razón usurpa el lugar del deseo y gobierna lo indeseado. El deseo al ser restringido gradualmente se hace pasivo hasta ser solo la sombra del deseo (El demonio es parco 2013, 31).

Es posible que los procesos de conflicto que vienen de la etapa conocida como "La Violencia" son replicados en las décadas siguientes por un problema aún no explorado: ausencia de la interiorización del deseo, de hacerlo nuestro, de reconocerlo. Los seres humanos no somos faros de luz ni de moral, ni la revolución demanda irreversiblemente de ello.

Pero no todo en aquella generación era verticalismo, ortodoxia. Las universidades se convierten en centros de estudios donde se forman profesionales integrales, no solo buenos ingenieros, sino buenos ciudadanos. En aquella época no es descabellado ver a un estudiante de ingeniería leyendo poesía, debatiendo sobre Gramsci y poniendo a pruebas sus habilidades artísticas en el mimeógrafo. La universidad es una zona de tolerancia, un corredor donde convergen [pero no habitan] todos los puntos de vista: desde los más anarquistas, pasando por los maoístas (en todos sus espectros) y llegando a los liberales y conservadores. La universidad era el momento de vivir: desde la apertura de sus puertas en la mañana hasta entrada la noche, los estudiantes querían ser parte de ella; el mundo de afuera tal vez les ofrecía muy poco, mientras que dentro del campus universitario se podía idealizar una revolución que entre pares parecía estar muy cerca, pero el mundo de afuera, el del campesino, el del obrero, tal vez anhelaba algo distinto. Pero muy pocas veces les preguntaron.

La consolidación de todo este proceso de rebeldía y anhelos de revolución se da en el año de 1971, cuando en medio de una profunda crisis política, de escasa legi- 
timidad con el presidente y con el uso indiscriminado de dispositivos como el estado de sitio, surge la propuesta de cogobierno que represente al estudiantado y al profesorado en las decisiones de las universidades. $\mathrm{Si}$ cincuenta años antes (1918) los estudiantes de Córdoba, Argentina, rechazaban el estancamiento y la mediocridad en la universidad, los estudiantes colombianos del 68 exigían una universidad comprometida con la autonomía, con el cambio social y el bienestar de todos.

La generación universitaria entre los años de 1971 y 1974 se podría considerar la más prolífica, propositiva y rebelde que vio la universidad en todo el siglo XX. Muchos estudiantes participaron activamente, no solo como eslabones en la protesta social o la movilización, sino como ideólogos, promotores y actores activos de lo que pasaría a la historia como el cogobierno universitario (Acevedo, La experiencia histórica del cogobierno en la Universidad Industrial de Santander, 2016, 67-100). Había líderes por montones en todas las universidades. Hoy casi medio siglo después, cuando comparten sus vivencias y observan con preocupación a las nuevas generaciones, sienten que estas ven la universidad como un requisito para entrar al ruedo de la movilidad social; una institución que los cambia de forma, pero no de fondo; un sitio en el que se gradúan, a diario, profesionales que no leen y menos imaginan. Bueno, siendo equilibrados, creo que hay que preguntarle a esta nueva generación si esto es así o no.

\section{El ocaso de la experiencia revolucionaria}

Es común pensar que la revolución no rindió sus frutos. El Mayo Francés abre las puertas a la burocratización con procesos tediosos en las universidades. Estudiantes de México son apresados, perseguidos; otros, cooptados por el Estado. En China se vive una revolución cultural encabezada por jóvenes guardias rojos, preámbulo de un estado totalitario y un capitalismo cada vez más vivo. La inspiración comunista de la Unión Soviética se desmorona en el año de 1989 y dos años después todo es un recuerdo opacado por el impulso ruso de adentrarse en un mundo neoliberal. El sistema logra que consumo sea igual a deseo y que incluso lo revolucionario sea lo novedoso y, por ende, costoso. El mercado de la especulación, las experiencias y el ocio convierten la cultura y la rebeldía en targets para vender artilugios que ayudan a huir del acontecer para entrar en el acontecer del consumo o de lo virtual.

En Colombia, la violencia que desencadena el narcotráfico, el paramilitarismo y la Guerra Sucia parecen devorar la universidad y todo rastro de pensamiento social, crítico y científico (Pécaut 2013). Ya no es necesario ser comunista, de izquierda o tradicional, cualquier persona que piense en mejorar las condiciones del otro es señalada, estigmatizada o pasada por el juicio exprés de jóvenes sicarios. Pese a todo, en los años setenta, y aún en los ochenta y noventa, no logran las voces autoritarias erradicar la rebeldía de la universidad, aunque sí muchas voces jóvenes deben emprender una travesía cual paria y llevar las ideas nuevas del 68 a sitios remotos. Esta iniciativa es tan sutil que es opacada por el ruido de los medios de comunicación. Iniciativas como los pies descalzos movilizaron miles de jóvenes de las universidades, públicas y privadas, a realizar trabajos de base, a preparar una revolución cultural y social en los lugares más alejados y olvidados tanto por el Estado como por la revolución.

Poco se conoce de este plan. Los estudiantes herederos del 68 dirigieron las protestas del 71 y 72 , de repente, se retiran al olvido. Ahora se recuerdan sus anécdotas en el Catatumbo comiendo iguana, o en Cartagena fundando barrios en las periferias, enseñando a leer en las escuelas pobres o creando grupos de teatro en pueblos que no tenían ni energía eléctrica. Estos rebeldes y utópicos sirvieron en silencio, algunos por meses, otros por años y unos más por décadas, para crear el concepto de una revolución cultural y social que no se ve a largo plazo, pero que muy seguramente permite recordar en algún lugar apartado del país a aquel "profe de ideas raras".

La universidad en el siglo XX de la mano de acontecimientos como el Manifiesto Liminar o la revolución cultural del 68 busca abrirse al otro, hacer parte política, social y científica de los problemas de las comunidades. Tal vez por lo poderosa y apasionante que es la palabra "revolución" no se logra lo que se idealiza o espera, pero sí hay un cambio. Somos hijos de la latencia; aún esperamos un macro acontecimiento que nos defina a todos y a cada uno, cuando ignoramos que aquella revolución de masas y de jóvenes en la calle derivó al mutismo y a la entrega de unos pocos, creyendo que el cambio es a largo plazo, con educación, cultura y ciencia. 


\section{El último "¡No más!" La apuesta por la vida}

La fuerza que toma la rebeldía es rápidamente combatida por el establishment a través de medidas violentas avaladas desde marcos de la legalidad, como son los estados de excepción; esta figura retoma las nociones del enemigo interno y las direcciona contra la lucha armada guerrillera y las acciones colectivas por parte de colectivos que protestan y justifican, desde un marco de legalidad, las acciones que en la normalidad del Estado serían vistas como ilegales, reprochables y violentas (Agamben 2006). Pero el problema inicia una vez superado el Estatuto de seguridad (1978-1982), cuando de nuevo la represión retorna por el mecanismo de la ilegalidad.

El encarcelamiento, represión, persecución y represión de estudiantes al ser vinculados con grupos guerrilleros, partidos comunistas y fuerzas ajenas al oficialismo adquieren dimensiones vulgares. Algunos de los dirigentes estudiantiles son condenados a la prisión y exilio en la Isla de Gorgona, mientras que otros son asesinados por encapuchados con armas automáticas y camionetas blindadas y dejan sus cuerpos en basureros de las principales ciudades del país al conocimiento de todos, como quien quiere dar una lección (Redacción el tiempo 1992). El clima de represión y persecución toma niveles alarmantes para finales de la década del 80. A esto se le suma el pesimismo por la disolución de la Unión Soviética, lo cual deja sin un horizonte político y sustrato ideológico la movilización que por casi medio siglo había dictaminado las esperanzas de cambio de una juventud rebelde.

Frente a esta coyuntura, los jóvenes en las universidades cambian el discurso y adoptan la defensa de un pro-común indistinto a cualquier ideología. El respeto a la vida, como se le denominó, conjuga la voz de alerta por las altas tasas de asesinatos, desapariciones y encarcelaciones, así como por los magnicidios políticos que buscan opacar cualquier alternativa política. Estas nuevas formas de movilización están enmarcadas dentro de los nuevos movimientos sociales y su máxima distancia con los anteriores es la búsqueda de un cambio desde lo político, en otras palabras, dejan de ser anti sistémicos (Negri 2006).

Entre los cambios sustanciales en las formas de movilización está el acercamiento hacia la población ajena a los targets universitarios, y esto lo hacen por medio de la difusión de las problemáticas sociales; es así como los jóvenes colombianos impulsan una consulta constituyente entre los años de 1989 y 1990 , acudiendo a medios masivos de comunicación como la radio y la prensa (J. Escobar 2011). Estas estrategias son tan eficientes que terminan catapultando a la juventud en un blanco político el cual exige, decide y de alguna manera rastrea el cambio. La búsqueda de nuevas formas de acción colectiva podría darse por la necesidad de un nuevo horizonte interpretativo y figurativo del futuro independiente al propuesto por el comunismo soviético; de nuevo la rebeldía sobrevive a los modelos económicos y se muestra como un referente personal y autónomo que apela a la libertad.

\section{Post Scriptum: presente-futuro, los retos de la movilización estudiantil colombiana}

Ahora bien, la represión no logra frenar la rebeldía y la movilización estudiantil; lo que sí la desdibuja es el neoliberalismo. Para este nuevo momento, el neoliberalismo no se debe entender como la alternativa económica de los 60 y 80 , que hace creer que cualquier forma de concertación es perdida y que la universidad es un estadio más en la carrera por la capitalización del sí-mismo (Gago 2014). Ahora, en el 2011, la lucha ya no es más por la represión del sistema, sino por la coacción a la que el sí-mismo se adhiere, y esto compromete la rebeldía y la libertad de los jóvenes.

Las luchas por las libertades de la década de 1960, acentuadas por la libertad sexual, la apropiación social de la revolución de la década de 1970 y la apuesta por los derechos comunes y la vida entre 1980 y 1990, caen en un mutismo soberbio que busca la capitalización del sí-mismo. A los jóvenes ya no les interesa ser un target político, solo le interesa ser un target de consumo y el aprovechamiento de las experiencias.

Aun con este panorama, los jóvenes colombianos volverán a estar en sintonía con los jóvenes del mundo en el año 2011. Esta vez no con un germen del 68 bautizado como "Prohibido prohibir" ni con una consigna como “¡No más!” Esta vez los jóvenes dicen: “indígnate!”, lo cual significa una invitación para cambiar la realidad y no conformarse con un sistema 
neoliberal que piensa en capitalizar. Al igual que con las experiencias de la década de los 90, fue en los medios de comunicación, esta vez independientes, que las juventudes vieron un "arma informática" para dar a conocer sus problemáticas. Esta vez plataformas como YouTube, Facebook y Twitter sirvieron para hacer "virales" sus iniciativas rebeldes (Acevedo y Correa, ¿Jóvenes e indignados? La movilización social estudiantil en el año 2011 2017).

Los retos para las movilizaciones estudiantiles y juveniles en el siglo XXI están relacionados con no perderse en el ruido y exceso de información producto de las Redes Sociales e Internet. Las experiencias de los indignados en el año 2011 en Colombia y el mundo demuestran la capacidad de movilizar personas y masificar contenidos; aun así, está el riesgo de la latencia, del olvido y de la pérdida de identificación del 68 con problemas comunes. Hoy circulan en la red múltiples concepciones de revolución y la libertad. Ahora bien, esto no afecta únicamente a la "juventud", la latencia es un problema generalizado que no permite ver ni siquiera el futuro, pues el presente es tan ancho que no consiente ver más allá del ahora.

\section{Bibliografía}

Acevedo, Álvaro, y Andrés Correa. (2017) “¿Jóvenes e indignados? La movilización social estudiantil en el año 2011." en Revista de Historia de la educación latinoamericana 19 (28).

Acevedo Tarazona, Álvaro. (2017) 1968: historia de un acontecimiento: Utopía y revolución en la universidad colombiana. Bucaramanga: Universidad Industrial de Santander. 698 pp.

. (2016) Memorias de una época: El movimiento estudiantil en Colombia en los años sesenta y setenta del siglo XX. Bucaramanga, Universidad Industrial de Santander. $530 \mathrm{pp}$.

. (2016) La experiencia histórica del cogobierno en la Universidad Industrial de Santander: Concepciones y divergencias en disputa por la autonomía universitaria, 1971-1976. Bucaramanga, UIS. 230 pp.

Agamben, Giorgio. (2006) Estado de excepción. Buenos Aires, Adriana Hidalgo.

Blake, William. (2013) El demonio es parco. Buenos Aires, Interzona.

Camus, Albert. (1982) El hombre rebelde. Barcelona, Alianza.

Debord, Guy. (2010) La sociedad del espectáculo. Madrid, Pre-textos.

Deleuze, Gilles. (1968) Différence et répétition. Paris, Presses Universitaires de France.

Escobar, Eduardo. (2005) entrevista de Marcos Herrera. Entrevista a Eduardo Escobar.

Escobar, Jorge. (2011) "La participación juvenil y la constitución." en Semana.

(2013) Diálogos. Valencia, Pre-textos.
Gago, Verónica. (2014) La razón neoliberal. Buenos Aires, Tinta Limón.

Gumbretch, Hans. (2015) Después de 1945: el origen de la latencia. Ciudad de México, Universidad Iberoamericana.

Jagger, Mick. (1968) Simpathy for the devil. Direc. Jellybean Benitez. Comps. Mick Jagger y Keith Richards.

Mejía, Juan Diego. (2016) Soñamos que vendrían por el mar. Bogotá, Alfaguara.

Negri, Antonio. (2006) Fin del invierno. Buenos Aires, Isla de la luna.

Nietzsche, Friedrich. (2006) Segunda consideración intempestiva. Buenos Aires, Libros del zorzal.

Pasolini, Paolo. (1968) Contra el PCI. Roma, s.f.

Pécaut, Daniel. (2013) La experiencia de la violencia: los desafíos del relato y la memoria. Medellín, La carreta.

Redacción el tiempo. (1992) "Asesinadas ayer nueve personas en dos matanzas." en El tiempo, 9 de julio.

Sancho, Roberto. (2008) La encrucijada de la violencia política armada en la segunda mitad del siglo XX en Colombia y España. Zaragoza, Universidad de Zaragoza.

Tünnermann, Carlos. (2008) Noventa años de la Reforma Universitaria de Córdoba. Buenos Aires, CLACSO.

Voz proletaria. (1976) "La pornografía un vicio del capitalismo." en Voz proletaria, mayo. 